\title{
COMPETÊNCIAS DOS EMPREENDEDORES EM UMA COOPERATIVA DE AGROINDÚSTRIAS FAMILIARES
}

\author{
ENTREPRENEURS SKILLS IN A FAMILY AGRIBUSINESS COOPERATIVE
}

Recebido: 27/03/2018 - Aprovado: 29/6/2018 - Publicado: 30/7/2018 Processo de Avaliação: Double Blind Review

\author{
Marcio Leandro da Silva 1 \\ Mestrando em Administração \\ Universidade Estadual do Oeste do Paraná \\ silvamarcioleandro@gmail.com \\ Cibely Delabeneta \\ Mestranda em Administração \\ Universidade Estadual do Oeste do Paraná \\ cibely_d@hotmail.com \\ Silvia de Almeida Boffi \\ Mestranda em Administração \\ Universidade Estadual do Oeste do Paraná \\ silvia.boffi@unioeste.br \\ Elza Hofer \\ Doutora em Administração \\ Professora do Mestrado Profissional em Administração \\ Universidade Estadual do Oeste do Paraná \\ elza_hofer@uol.com.br
}

\begin{abstract}
RESUMO: O estudo objetivou identificar as competências empreendedoras presentes nos produtores rurais ou que exploram a atividade agroindustrial. Os dados foram coletados por meio de survey, no qual aplicou-se o instrumento de pesquisa que foi adaptado do modelo de Lenzi (2008). A amostra foi de 27 associados de uma cooperativa de agroindústrias da região oeste do Paraná. Dentre as competências analisadas, os maiores destaques foram as variáveis "persistência" e "comprometimento" que estavam presentes em 100\% dos respondentes. Destacou-se a competência "empreendedora para sustentabilidade" com 96,30\%, seguida pelas competências "estabelecimento de metas" e "exigência de qualidade e eficiência" com $88,89 \%$ de participação para ambas. Para a identificação da existência de determinada competência, essa é obtida pela soma da escala, com pontuação mínima de 12 pontos (Lenzi, 2008). Resultados indicam que os pesquisados possuem competências empreendedoras, pois somente a competência "busca de oportunidades e iniciativa" obteve 11,63 pontos. As demais variáveis ultrapassaram a escala mínima sugerida. O estudo possibilitou a análise da relação entre competências
\end{abstract}

\footnotetext{
${ }^{1}$ Autor para correspondência: UNIOESTE: Universidade Estadual do Oeste do Paraná. Rua Universitária, 2069 - Sala 78 - $3^{\circ}$ andar - Jardim Universitário - Cascavel - PR - Cep: 85819-110. Brasil.
} 
com o faturamento e a escolaridade. A contribuição deste estudo foi a identificação do perfil empreendedor de pequenos produtores rurais e/ou agroindustriais e a influência dessas competências no desenvolvimento de suas atividades para o fortalecimento do agronegócio local.

Palavras-chave: sustentabilidade; competências empreendedoras; cooperativismo.

ABSTRACT: The study aimed at identifying the entrepreneurial skills present in the rural producers or those who explore the agribusiness activity. The pieces of information were collected through a survey, whose research instrument was adapted from the Lenzi model (2008). The sample cam from 27 associates of an agribusiness cooperative of the western region of Paraná. Among the competences analyzed, the most emphasized were the variables "persistence" and "impairment" that were found in 100\% of the respondents. The "entrepreneurship for sustainability" competence was highlighted with $96.30 \%$, followed by the competencies "goal setting" and "quality and efficiency requirement" with $88.89 \%$ participation for both. For the identification of the existence of a certain competence, this is obtained by the sum of the scale, with a minimum score of 12 points (Lenzi, 2008). Results indicate that the respondents have entrepreneurial skills, due to the fact that only the competence "search for opportunities and initiative" obtained 11.63 points, the other variables exceeded the minimum suggested scale. The study made it possible to analyze the relationship between competencies with turnover and schooling. The contribution of this study was the identification of the entrepreneurial profile of small rural and / or agribusiness producers and the influence of these skills in the development of their activities to strengthen local agribusiness.

Keywords: sustainability; entrepreneurial skills; cooperativism.

\section{INTRODUÇÃ̃O}

O aumento gradativo da população mundial e, sua consequente demanda por alimentos, leva-nos a uma previsão de que o Brasil alcançará o patamar de líder global no fornecimento de alimentos e commodities ligadas ao agronegócio, solidificando sua economia e impulsionando seu crescimento (BACHA, 2012). O Brasil apresentou um crescimento econômico acentuado nas últimas décadas, sendo que grande parte desse crescimento se deve às atividades agrícolas (ABBADE, 2014).

A tecnologia de processo aumenta a produtividade da terra, do trabalho, do capital e reduz o custo médio de produção, mas exigem investimentos, conhecimentos, escala mínima de produção e as chances de competir aumentam com o associativismo (STEFANELO, 2008). O agronegócio compõe-se de cadeias produtivas e, essas possuem, entre seus componentes, os sistemas produtivos que operam em diferentes ecossistemas ou sistemas naturais. Nesse cenário, existe um conglomerado de instituições de apoio, 
composto de instituições de crédito, pesquisa, assistência técnica, entre outras, e um aparato legal e normativo, exercendo forte influência no desempenho do agronegócio (CASTRO, 2000).

Com as necessidades de melhorias nos índices de produtividade no agronegócio, surgiram as cooperativas como importantes agentes de transformação que são originadas a partir da união de pessoas com objetivos em comum. As sociedades cooperativas desempenham importante papel na sociedade ao prover recursos e subsídios aos seus cooperados para o crescimento e manutenção do agronegócio.

A atuação das cooperativas pode ser definida a partir de uma doutrina econômica, cujo o objetivo é sustentar a associação livre e autônoma de pessoas, cujos interesses são comuns, com característica solidária para atingir as necessidades individuais e coletiva, com ganhos de escala e agregação de valor por meio das atividades desenvolvidas no seguimento do agronegócio (TARIFA; SCHALLENBERER, 2016).

O potencial econômico das cooperativas agropecuárias brasileiras tem um significativo aumento, e isso vem sendo evidenciado em nível mundial, pois o Brasil vem conquistando mercado de forma progressiva. $\mathrm{O}$ aumento do potencial econômico reflete em desenvolvimento e crescimento das atividades de cunho social, econômico e ambiental em nível local, regional e nacional, permeando assim a sustentabilidade no âmbito do agronegócio (PROTIL BENEDITO; SOUZA, 2009).

A criação das cooperativas é de fundamental importância para a comercialização da produção familiar. Os produtores rurais também se beneficiam com a venda direta de seus produtos em suas propriedades, evitando a ação dos atravessadores e intermediadores (Blanco, 2006).

De acordo com Blanco (2006), as novas atividades rurais estão desenvolvendo a mentalidade do empreendedorismo rural, contribuindo para que as propriedades familiares passem a ser encaradas como sistemas produtivos e orgânicos onde são agregadas novas atividades interligadas e integradas trazendo benefícios reais à geração de emprego e renda no campo.

Conforme Schumpeter (1982), o empreendedor é aquele que realiza novas combinações. É o agente das inovações e deve ter capacidade de desenvolver novos negócios que envolvem a previsão, a iniciativa e a liderança. 
Tendo em vista essas considerações, o objetivo da pesquisa da qual deriva o presente trabalho foi investigar o perfil empreendedor dos associados de uma cooperativa de agroindústrias familiares da região oeste do Paraná por meio do mapeamento das competências presentes no empreendedor.

\section{REVISÃO TEÓRICA}

Esta seção apresenta os seguintes fundamentos teóricos: sustentabilidade, agronegócio, empreendedorismo, competências do empreendedor e cooperativismo agroindustrial.

\subsection{SUSTENTABILIDADE}

Para Barbieri (2007), sustentabilidade é a capacidade de um modelo ou sistema se sustentar na dinâmica evolutiva, não permitindo que algum setor se aprofunde em crises, de tal forma que venha a atingir a totalidade. Trata-se de um conceito sistêmico, relacionado com os aspectos econômicos, sociais, culturais e ambientais.

Aligleri, Aligeri e Kruglianskas (2009) alegam que pesquisadores afirmam que há diferentes práticas agrícolas que visam aumento da produtividade, retorno econômico e menor impacto ambiental, podendo ser focadas no desenvolvimento sustentável e abrangendo a eficiência tecnológica, redução do uso de agroquímicos, energia, água, promovendo a conservação de recursos naturais e da biodiversidade. Considerando que os principais recursos utilizados para produção de alimentos são renováveis, como água, sementes, solo, entre outros, é fundamental a implantação de processos eficientes de controle e monitoramento da expansão agrícola, de modo a reduzir os processos de degradação ambiental tornando as atividades menos impactantes.

O tema sustentabilidade passa a moldar as atividades organizacionais e obriga as empresas a ajustarem suas ações, envolvendo os pilares econômico, social, ambiental e cultural (FERREIRA, 2017). Brandalise et al. (2017) salientam que cada vez mais empresas adotam processos produtivos que causam menor dano ambiental. Tais mudanças são reflexo de acordos e protocolos internacionais firmados, suportados pelas pressões de grupos ambientalistas e de consumidores conscientes.

As práticas sustentáveis são capazes de manter a proteção da biodiversidade nas áreas cultiváveis, reduzindo o uso de pesticidas e melhorando a conservação dos recursos 
naturais e da produtividade dessas áreas, o que, ocasionalmente, reduz drasticamente os impactos gerados pela produção em larga escala e otimizam a produção com o aumento do lucro no agronegócio.

\subsection{AGRONEGÓCIO}

O sucesso do agronegócio se deve à união de esforços de agricultores, das cooperativas, das agências governamentais e de empresas privadas (ZANELLA et al., 2016).

O agronegócio está intrinsecamente vinculado ao conjunto de atividades da agropecuária (BACHA, 2004). Complementando, Soares e Jacometti (2015) destacam que o agronegócio é uma agregação de atividades divididas estruturalmente em quatro segmentos, compreendendo os fornecedores de insumos, as atividades que orbitam em torno da agropecuária, os processos de transformação da agroindústria e as operações de armazenagem, transporte e distribuição.

Corroborando, Gasques et al. (2004) relatam que o agronegócio em sua cadeia produtiva engloba desde a fabricação de insumos, passando pela produção nos estabelecimentos agropecuários e pela sua transformação, até o seu consumo. Além disso, a cadeia produtiva compreende diversos serviços, sendo os principais a pesquisa agropecuária e assistência técnica, processamento, transporte, comercialização, crédito, exportação, serviços portuários, distribuidores, bolsas, industrialização e o consumidor final.

Os autores destacam ainda que o agronegócio configura um segmento de grande relevância para a economia do Brasil, abrangendo outras atividades de suporte na cadeia de valor e ainda, além de gerar emprego e renda, o setor contribui fortemente para a estabilidade econômica, ajudando a amenizar o déficit comercial originado de outros setores produtivos. Segundo Castro (2016), a ausência de invernos rigorosos e a extensão do território brasileiro são características favoráveis do setor para o desenvolvimento da economia nacional.

Poucos negócios correm riscos comparáveis aos do agronegócio. Se assumir riscos é a principal característica das pessoas empreendedoras, a figura do agricultor representa um grande exemplo de empreendedor. 


\subsection{EMPREENDEDORISMO}

De acordo com a Lei número 11.326/2006, são considerados como agricultor familiar ou empreendedor familiar rural aquele que pratica atividades no meio rural, possui área de até quatro módulos fiscais, mão de obra da própria família, renda familiar vinculada ao próprio estabelecimento e gerenciamento do estabelecimento ou empreendimento pela própria família. Segundo Dalmoro et al. (2017), a agricultura familiar é formada por um arranjo social particular de produção, com relações baseadas em laços de parentesco e/ou afetivos de vizinhança.

Souza e Guimarães (2006) destacam que empreendedorismo é um conceito dinâmico em que o empreendedor se destaca ou surge quando aparecem novas situações, novas decisões são tomadas ou ainda quando novos rumos são escolhidos.

Baron e Shane (2010) definem que empreendedorismo é um processo, com as fases: geração de ideia para nova empresa e/ou reconhecimento de uma oportunidade; reunião de recursos necessários para desenvolver a oportunidade e lançamento do novo empreendimento.

Oliveira (1995) afirma que o empreendedor é uma mistura de muitos ingredientes, sendo essa mistura não homogênea para todos os empreendedores. Cada empreendedor tem alguns ingredientes em especial. O empreendedorismo se tornou objeto de estudo mundial, por ser um dos principais responsáveis pelo desenvolvimento econômico e, consequentemente, social dos países (SILVEIRA; PASSOS; MARTINS, 2017).

No empreendedorismo, é preciso levar em conta o perfil do empreendedor e as capacidades que ele adquire com a experiência, pois isso está relacionado com o seu sucesso ou fracasso. Assim, quem quer se destacar no mercado deve procurar conhecer e desenvolver competências empreendedoras.

\subsection{COMPETÊNCIAS DOS EMPREENDEDORES}

Há diversos autores e abordagens empreendedoras, independentes e corporativas, Lenzi (2007) organizou as principais características e competências de empreendedores em um quadro, fazendo relação com as competências empreendedoras apontadas por Spencer e Spencer e Cooley, que foram consideradas como base conceitual para a elaboração do instrumento de coleta de dados. 
Quadro 1: Relação das competências empreendedoras, autores e abordagem de Spencer e Spencer (1993) e Cooley (1990):

\begin{tabular}{|c|c|c|}
\hline AUTOR & PRINCIPAIS COMPETÊNCIAS & $\begin{array}{c}\text { COMPETENNCIAS EMPREENDEDORAS } \\
\text { Spencer e Spencer (1993) e Cooley (1990) }\end{array}$ \\
\hline Mill (1848) & Tolerância ao risco & $\begin{array}{l}\begin{array}{l}\text { Correr riscos calculados, busca de } \\
\text { informações }\end{array} \\
\end{array}$ \\
\hline Weber (1917) & Origem da autoridade formal & \\
\hline $\begin{array}{l}\text { Schumpeter } \\
(1928,1934, \\
1942,1949,1967, \\
1982)\end{array}$ & $\begin{array}{l}\text { Inovação, iniciativa, sonho, } \\
\text { criatividade, energia, } \\
\text { realização pessoal, poder, } \\
\text { mudança }\end{array}$ & $\begin{array}{l}\text { Busca de oportunidades e iniciativa, } \\
\text { persistência, comprometimento, persuasão } \\
\text { e rede de contatos, independência e } \\
\text { autoconfiança }\end{array}$ \\
\hline Sutton (1954) & Busca de responsabilidade & Comprometimento \\
\hline Hartman (1959) & Busca de autoridade formal & \\
\hline $\begin{array}{l}\text { McClelland } \\
(1961,1971 \\
1973)\end{array}$ & $\begin{array}{l}\text { Tomador de risco, necessidade de } \\
\text { realização, necessidade de } \\
\text { afiliação }\end{array}$ & $\begin{array}{l}\text { Busca de oportunidades e iniciativa, correr } \\
\text { riscos calculados, persuasão e rede de } \\
\text { contatos, independência e autoconfiança }\end{array}$ \\
\hline Davids (1963) & $\begin{array}{l}\text { Ambição, desejo de } \\
\text { independência, responsabilidade e } \\
\text { autoconfiança }\end{array}$ & $\begin{array}{l}\text { Busca de oportunidades e iniciativa, } \\
\text { comprometimento, independência e } \\
\text { autoconfiança }\end{array}$ \\
\hline Pickle (1964) & $\begin{array}{l}\text { Relacionamento humano, } \\
\text { habilidade de comunicação, } \\
\text { conhecimento técnico }\end{array}$ & $\begin{array}{l}\text { Exigência de qualidade e eficiência, busca } \\
\text { de informações, persuasão e rede de } \\
\text { contatos }\end{array}$ \\
\hline $\begin{array}{l}\text { Palmer } \\
(1971)\end{array}$ & Avaliador de riscos & $\begin{array}{l}\text { Correr riscos calculados, busca de } \\
\text { informações }\end{array}$ \\
\hline $\begin{array}{l}\text { Hornaday e } \\
\text { Aboud (1971) }\end{array}$ & $\begin{array}{l}\text { Necessidade de realização, } \\
\text { autonomia, agressão, poder, } \\
\text { reconhecimento, inovação, } \\
\text { independência }\end{array}$ & $\begin{array}{l}\text { Busca de oportunidades e iniciativa, } \\
\text { persistência, persuasão e rede de contatos, } \\
\text { independência e autoconfiança }\end{array}$ \\
\hline $\begin{array}{l}\text { Winter } \\
(1973)\end{array}$ & Necessidade de poder & $\begin{array}{llll}\text { Persuasão e rede de contatos, } \\
\text { independência e autoconfiança }\end{array}$ \\
\hline Borland (1974) & Controle interno & $\begin{array}{l}\text { Exigência de qualidade e eficiência, busca } \\
\text { de informações, estabelecimento de metas, } \\
\text { planejamento e monitoramento } \\
\text { sistemáticos }\end{array}$ \\
\hline Liles (1974) & Necessidade de realização & $\begin{array}{l}\text { Busca de oportunidades e iniciativa, } \\
\text { persistência, comprometimento }\end{array}$ \\
\hline Bruce (1976) & Tomada de decisões, risco & $\begin{array}{lcr}\text { Correr riscos } & \text { calculados, exigência } & \text { de } \\
\text { qualidade e eficiência, busca } & \text { de } \\
\text { informações, } & \text { independência } & \text { e } \\
\text { autoconfiança } & & \\
\end{array}$ \\
\hline $\begin{array}{l}\text { Shapero }(1977, \\
1980)\end{array}$ & $\begin{array}{l}\text { Inovação, risco, } \\
\text { iniciativa, independência }\end{array}$ & $\begin{array}{l}\text { Busca de oportunidades e iniciativa, } \\
\text { correr riscos calculados, persistência, } \\
\text { comprometimento, independência e } \\
\text { autoconfiança }\end{array}$ \\
\hline Gasse (1977) & Orientado por valores pessoais & Comprometimento \\
\hline Timmons (1978) & $\begin{array}{l}\text { Autoconfiança, orientado por } \\
\text { metas, tomador de riscos } \\
\text { moderados, centro de } \\
\text { controle, criatividade, } \\
\text { inovação }\end{array}$ & $\begin{array}{l}\text { Busca de oportunidades e iniciativa, } \\
\text { correr riscos calculados, persistência, } \\
\text { busca de informações, estabelecimento } \\
\text { de metas, planejamento sistemáticos, } \\
\text { monitoramento } \\
\text { independência e autoconfiança }\end{array}$ \\
\hline Cantillon ( 1978) & Inovação & $\begin{array}{l}\text { Busca de oportunidades e iniciativa, } \\
\text { independência e autoconfiança }\end{array}$ \\
\hline Sexton (1980) & Enérgico, ambicioso, revés positivo & $\begin{array}{l}\text { Busca de oportunidades e iniciativa, } \\
\text { persistência, independência }\end{array}$ \\
\hline
\end{tabular}




\begin{tabular}{|c|c|c|}
\hline & & autoconfiança \\
\hline $\begin{array}{l}\text { Welsh e White } \\
\text { (1981) }\end{array}$ & $\begin{array}{l}\text { Necessidade de controle, } \\
\text { responsabilidade, } \\
\text { autoconfiança, corredor de } \\
\text { riscos moderados }\end{array}$ & $\begin{array}{lc}\text { Correr riscos } & \text { calculados, } \\
\text { comprometimento, } & \text { planejamento e } \\
\text { monitoramento } & \text { sistemáticos, } \\
\text { independência e autoconfiança }\end{array}$ \\
\hline $\begin{array}{l}\text { Dunkelberg e } \\
\text { Cooper (1982) }\end{array}$ & $\begin{array}{l}\text { Orientado ao crescimento, } \\
\text { profissionalização e independência }\end{array}$ & $\begin{array}{l}\text { Busca de oportunidades e iniciativa, } \\
\text { exigência de qualidade e eficiência, } \\
\text { persistência, independência } \\
\text { autoconfiança }\end{array}$ \\
\hline $\begin{array}{l}\text { Pinchot }(1985,1989, \\
2004)\end{array}$ & Visão, execução, planejamento & $\begin{array}{l}\text { Busca de oportunidades e iniciativa, } \\
\text { persistência, comprometimento, } \\
\text { estabelecimento de metas, planejamento } \\
\text { e monitoramento sistemáticos }\end{array}$ \\
\hline $\begin{array}{l}\text { Filion }(1988,1991, \\
1993,1999)\end{array}$ & $\begin{array}{l}\text { Visão, imaginação, } \\
\text { oportunidade, objetivos }\end{array}$ & $\begin{array}{l}\text { Busca de oportunidades e iniciativa, } \\
\text { correr riscos calculados, estabelecimento } \\
\text { de metas }\end{array}$ \\
\hline Zahra (1991) & $\begin{array}{l}\text { Renovação estratégica, } \\
\text { novos negócios }\end{array}$ & $\begin{array}{l}\text { Busca de oportunidades e iniciativa, } \\
\text { correr riscos calculados, planejamento e } \\
\text { monitoramento sistemáticos }\end{array}$ \\
\hline $\begin{array}{l}\text { Cunningham e } \\
\text { Lischeron (1991) }\end{array}$ & Liderança, ação, risco, inovação & $\begin{array}{l}\text { Busca de oportunidades e iniciativa, } \\
\text { correr riscos calculados, persuasão e } \\
\text { rede de contatos, independência e } \\
\text { autoconfiança }\end{array}$ \\
\hline Farrel (1993) & Visão, valores pessoais & $\begin{array}{l}\text { Busca de oportunidades e iniciativa, } \\
\text { comprometimento }\end{array}$ \\
\hline Cossete (1994) & Visão, formulação de estratégias & $\begin{array}{l}\text { Busca de oportunidades e iniciativa, } \\
\text { planejamento e monitoramento } \\
\text { sistemáticos }\end{array}$ \\
\hline Miner (1998) & $\begin{array}{l}\text { Realização, rede de } \\
\text { relacionamento, novas } \\
\text { ideias, administração }\end{array}$ & 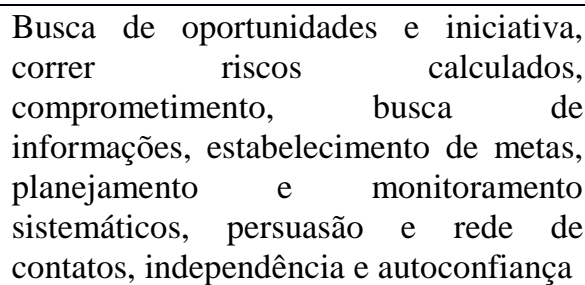 \\
\hline $\begin{array}{l}\text { Sharma e } \\
\text { Chrisman (1999) }\end{array}$ & Criação, inovação & Busca de Oportunidades e Iniciativa \\
\hline Dolabela (1999) & $\begin{array}{l}\text { Inovação, criatividade, visão, } \\
\text { planejamento, iniciativa, } \\
\text { oportunidade }\end{array}$ & $\begin{array}{l}\text { Busca de oportunidades e iniciativa, } \\
\text { busca de informações, estabelecimento } \\
\text { de metas, planejamento e monitoramento } \\
\text { sistemáticos }\end{array}$ \\
\hline $\begin{array}{l}\text { Fleury }(2000, \\
2002)\end{array}$ & $\begin{array}{l}\text { Ação, mobilização de recursos, } \\
\text { entrega, engajamento, } \\
\text { responsabilidade, visão } \\
\text { estratégica }\end{array}$ & $\begin{array}{l}\text { Busca de oportunidades e iniciativa, } \\
\text { correr riscos calculados, exigência de } \\
\text { qualidade e eficiência, persistência, } \\
\text { comprometimento, planejamento e } \\
\text { monitoramento sistemáticos, persuasão e } \\
\text { rede de contatos, independência e } \\
\text { autoconfiança }\end{array}$ \\
\hline $\begin{array}{l}\text { Klerk e Kruger } \\
(2003)\end{array}$ & $\begin{array}{l}\text { Inovação, criatividade, visão de } \\
\text { futuro, condição de assumir riscos, } \\
\text { determinaça,o, valores, } \\
\text { adaptabilidade, prontidão, firmeza, } \\
\text { ambição, suficiência de capital }\end{array}$ & $\begin{array}{l}\text { Busca de oportunidades e iniciativa, } \\
\text { correr riscos calculados, exigência de } \\
\text { qualidade e eficiência, persistência, } \\
\text { comprometimento, independência e } \\
\text { autoconfiança }\end{array}$ \\
\hline Dornelas (2003) & $\begin{array}{l}\text { Oportunidade, criação, } \\
\text { iniciativa, inovação, }\end{array}$ & $\begin{array}{l}\text { Busca de oportunidades e iniciativa, } \\
\text { correr riscos calculados, persistência, }\end{array}$ \\
\hline
\end{tabular}

REMIPE- Revista de Micro e Pequenas Empresas e Empreendedorismo da Fatec Osasco 


\begin{tabular}{|c|c|c|}
\hline & $\begin{array}{l}\text { gerenciamento do risco, } \\
\text { planejamento, persistência, } \\
\text { relacionamentos }\end{array}$ & $\begin{array}{l}\text { busca de informações, estabelecimento } \\
\text { de metas, planejamento e } \\
\text { monitoramento sistemáticos, persuasão } \\
\text { e rede de contatos, independência e } \\
\text { autoconfiança }\end{array}$ \\
\hline Santos (2004) & $\begin{array}{l}\text { Criatividade, inovação, } \\
\text { novos negócios }\end{array}$ & $\begin{array}{l}\text { Busca de oportunidades e iniciativa, } \\
\text { comprometimento, independência e } \\
\text { autoconfiança }\end{array}$ \\
\hline $\begin{array}{l}\text { Seifert }(2004, \\
2005)\end{array}$ & $\begin{array}{l}\text { Criatividade, inovação, } \\
\text { novos negócios, renovação } \\
\text { estratégica }\end{array}$ & $\begin{array}{l}\text { Busca de oportunidades e iniciativa, } \\
\text { comprometimento, planejamento e } \\
\text { monitoramento } \\
\text { independência e autoconfiança }\end{array}$ \\
\hline Dutra (2004) & $\begin{array}{l}\text { Capacidade de inovação, } \\
\text { comunicação, liderança, resolução } \\
\text { de problemas, direcionamento } \\
\text { estratégico, negociação, } \\
\text { planejamento, relacionamentos, } \\
\text { visão sistêmica, orientação para } \\
\text { qualidade }\end{array}$ & $\begin{array}{l}\text { Busca de oportunidades e iniciativa, } \\
\text { exigência de qualidade e eficiência, } \\
\text { comprometimento, busca de } \\
\text { informações, estabelecimento de metas, } \\
\text { planejamento e monitoramento } \\
\text { sistemáticos, persuasão e rede de } \\
\text { contatos, independência e autoconfiança }\end{array}$ \\
\hline
\end{tabular}

Fonte: Lenzi (2008).

No quadro 1, foi possível visualizar o destaque das principais competências em diversos estudos, identificando as competências apontadas por Spencer e Cooley, demonstrando a consistência dos mesmos, reforçando assim a abordagem a ser utilizada. Destaca-se das competências apontadas, a busca de oportunidades e iniciativa, persistência, comprometimento, independência e autoconfiança.

Ilustrando esses destaques no quadro 2, Lenzi (2008) identifica a incidência de estudos realizados com similaridade das competências desenvolvidas por Spencer e Spencer e Cooley, mostrando quais autores apontam com relevância cada uma delas:

Quadro 2 - Relação das competências empreendedoras, autores e abordagem de Spencer e Spencer (1993) e Cooley (1990):

\begin{tabular}{|c|c|}
\hline $\begin{array}{l}\text { COMPETÊNCIAS } \\
\text { EMPREENDEDORAS } \\
\text { Spencer e Spencer (1993) e } \\
\text { Cooley (1990) }\end{array}$ & $\begin{array}{l}\text { COMPETÊNCIAS } \\
\text { Outros Autores }\end{array}$ \\
\hline $\begin{array}{l}\text { Busca de Oportunidades e } \\
\text { Iniciativa }\end{array}$ & $\begin{array}{l}\text { Schumpeter (1928, 1934, 1942, 1949, 1967, 1982); McClelland } \\
\text { (1961, 1971, 1973); Davids (1963); Hornaday e Aboud (1971); } \\
\text { Liles (1974); Shapero (1977, 1980); Timmons (1978); Cantillon } \\
\text { (1978); Sexton (1980); Dunkelberg e Cooper (1982); } \\
\text { Pinchot (1985, 1989, 2004); Drucker (1986, 2002); Filion } \\
\text { (1988, 1991, 1993, 1999); Zahra (1991); Cunningham e } \\
\text { Lischeron (1991); Farrel (1993); Cossete (1994); Miner (1998); } \\
\text { Sharma e Chrisman (1999); Dolabela (1999); Fleury (2000, } \\
\text { 2002); Klerk e Kruger (2003); Dornelas (2003); Santos } \\
\text { (2004); Seifert (2004, 2005); } \\
\text { Dutra (2004). }\end{array}$ \\
\hline
\end{tabular}

REMIPE- Revista de Micro e Pequenas Empresas e Empreendedorismo da Fatec Osasco 


\begin{tabular}{|c|c|}
\hline Correr Riscos Calculados & $\begin{array}{l}\text { Mill (1848); McClelland (1961, 1971, 1973); Palmer (1971); } \\
\text { Bruce (1976); Shapero (1977, 1980); Timmons (1978); Welsh e } \\
\text { White (1981); Filion (1988, 1991, 1993, 1999); Zahra } \\
\text { (1991); Cunningham e Lischeron (1991); Miner (1998); Fleury } \\
\text { (2000, 2002); Klerk e Kruger (2003); Dornelas (2003). }\end{array}$ \\
\hline $\begin{array}{l}\text { Exigência de Qualidade e } \\
\text { Eficiência }\end{array}$ & $\begin{array}{l}\text { Pickle (1964); Borland (1974); Bruce (1976); Dunkelberg e } \\
\text { Cooper (1982); Fleury (2000, 2002); Klerk e Kruger (2003); Dutra } \\
\text { (2004). }\end{array}$ \\
\hline Persistência & 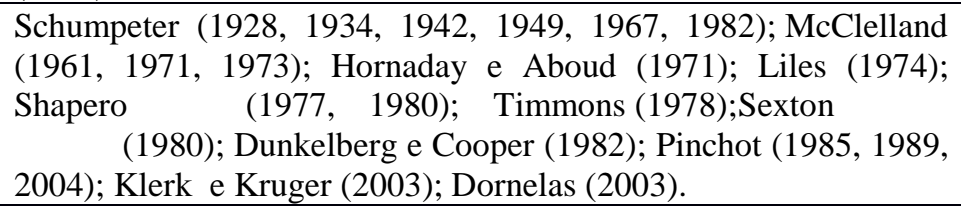 \\
\hline Comprometimento & $\begin{array}{l}\text { Schumpeter (1928, 1934, 1942, 1949, 1967, 1982); Sutton (1954); } \\
\text { Davids (1963); Liles (1974); Shapero (1977, 1980); Gasse (1977); } \\
\text { Welsh e White (1981); Pinchot (1985, 1989, 2004); Farrel (1993); } \\
\text { Miner (1998); Fleury (2000, 2002); Klerk e Kruger (2003); Seifert } \\
(2004,2005) \text {; Dutra (2004). }\end{array}$ \\
\hline Busca de Informações & $\begin{array}{l}\text { Mill (1848); Pickle (1964); Palmer (1971); Borland (1974); Bruce } \\
\text { (1976); Timmons (1978); Dolabela (1999); Dornelas (2003); Dutra } \\
\text { (2004). }\end{array}$ \\
\hline Estabelecimento de Metas & $\begin{array}{l}\text { Borland (1974); Timmons (1978); Pinchot (1985, 1989, 2004); } \\
\text { Filion (1988, 1991, 1993, 1999); Miner (1998); Dolabela (1999); } \\
\text { Dornelas (2003); Dutra (2004). }\end{array}$ \\
\hline $\begin{array}{l}\text { Planejamento e } \\
\text { Monitoramento } \\
\text { Sistemáticos }\end{array}$ & $\begin{array}{l}\text { Borland (1974); Timmons (1978); Welsh e White (1981); Pinchot } \\
\text { (1985, 1989, 2004); Zahra (1991); Cossete (1994); Miner (1998); } \\
\text { Dolabela (1999); Fleury (2000, 2002); Dornelas (2003); Seifert } \\
\text { (2004, 2005); Dutra (2004). }\end{array}$ \\
\hline Persuasão e Rede de Contatos & $\begin{array}{l}\text { Schumpeter (1928, 1934, 1942, 1949, 1967, 1982); McClelland } \\
\text { (1961, 1971, 1973); Pickle (1964); Hornaday e Aboud (1971); } \\
\text { Winter (1973); Cunningham e Lischeron (1991); Miner (1998); } \\
\text { Fleury (2000, 2002); Dornelas (2003); Dutra (2004). }\end{array}$ \\
\hline Independência e Auto Confiança & $\begin{array}{l}\text { Schumpeter (1928, 1934, 1942, 1949, 1967, 1982); McClelland } \\
\text { (1961, 1971, 1973); Davids (1963); Hornaday e Aboud (1971); } \\
\text { Winter (1973); Bruce (1976); Shapero (1977, 1980); Timmons } \\
\text { (1978); Cantillon (1978); Sexton (1980); Welsh e White (1981); } \\
\text { Dunkelberg e Cooper (1982); Cunningham e Lischeron (1991); } \\
\text { Miner (1998); Fleury (2000, 2002); Klerk e Kruger (2003); } \\
\text { Dornelas (2003); Santos (2004); Seifert (2004, 2005); Dutra } \\
\text { (2004). }\end{array}$ \\
\hline
\end{tabular}

Fonte: Lenzi (2008).

Um empreendedor pode se unir a outros empreendedores, a fim de realizar um projeto, juntando forças para idealizá-lo, planejá-lo e executá-lo. Havendo mais opiniões a debater, gerando discussões, que podem ser o ponto de partida para o aperfeiçoamento de muitos projetos e produtos, seguindo os próprios princípios cooperativistas. 


\subsection{COOPERATIVISMO AGROINDUSTRIAL}

De acordo com a Organização das Cooperativas Brasileiras (OCB), em seu relatório publicado em 2013, cerca de 11 milhões de brasileiros participam de algum ramo cooperativo, sendo que mais de 1 milhão desses correspondem ao ramo agropecuário. Neste sentido, a agroindústria vem obtendo importância cada vez maior no processo de desenvolvimento pela possibilidade de gerar maior valor agregado à produção do meio rural, além de reunir a economia do campo ao sistema industrial, considerando que a agricultura e a indústria juntas multiplicam as potencialidades de geração de renda e de emprego na região em que elas se inserem (SILVA; PEIXOTO; KHAN, 2008).

Mello e Schneider (2013, p. 13) corroboram ao destacar as oportunidades de negócios na agroindústria familiar:

\footnotetext{
Criam-se novas oportunidades de inserção no mercado de uma produção que não é estranha aos colonos da região pois faz parte da sua cultura, da sua história e do seu cotidiano. Trata-se da transformação/beneficiamento ou industrialização da produção agropecuária com o objetivo principal de comercializar o produto assim obtido. A agroindústria familiar rural caracteriza-se pela sua localização no meio rural, a maior parte da matériaprima é de origem própria, utiliza máquinas e equipamentos mais simples e, em geral, a produção se dá por processos artesanais.
}

Possenti (2010) destaca que o setor agroindustrial de pequeno porte está sujeito a descontinuidade do empreendimento devido a sua produção em pequena escala e individualizada. $\mathrm{O}$ autor ressalta que o cooperativismo, sendo esse uma das formas associativas, fortalece as agroindústrias familiares dado o aumento da escala de produção.

\section{METODOLOGIA}

A presente pesquisa caracteriza-se, de acordo com Silveira e Córdova (2009), como qualitativa, quanto à abordagem, e exploratória descritiva, quanto aos objetivos. Em relação ao procedimento, pode ser caracterizada como bibliográfica e documental, sendo uma revisão de teorias sobre o tema proposto. Será associada uma pesquisa de campo, com o objetivo de levantar informações relacionadas ao perfil empreendedor dos associados da cooperativa proprietários das agroindústrias familiares, objeto do presente estudo.

REMIPE- Revista de Micro e Pequenas Empresas e Empreendedorismo da Fatec Osasco 
A pesquisa se deu em etapas, sendo a primeira realizada por meio de consulta a fontes de dados secundárias, com objetivo de realizar a identificação de conceitos de sustentabilidade, agronegócio, empreendedorismo, competências empreendedoras e cooperativismo agroindustrial.

$\mathrm{Na}$ segunda etapa, realizou-se a aplicação de questionário fechado para 27 associados da cooperativa que possuíam agroindústrias e/ou propriedades sustentadas por meio da mão de obra familiar. A amostragem selecionada foi não probabilística por conveniência, modalidade de amostragem em que o pesquisador seleciona os elementos a que tem acesso, admitindo que esses possam representar um universo representativo (LEVY e LEMESHOW, 1980).

Cabe evidenciar que a cooperativa objeto do estudo declarou aos pesquisadores possuir registrado em seu quadro societário 98 cooperados, porém, ressaltou que grande parte desses, foram considerados inativos, com base nos históricos de operações que os produtores movimentam por meio da sociedade cooperativa.

Quanto aos procedimentos de coleta de dados, trata-se de levantamento ou survey, que conforme Santos (1999), é a pesquisa que busca informação diretamente com um grupo de interesse a respeito dos dados que se deseja obter. A coleta foi realizada no período dos meses de janeiro e fevereiro do ano de 2018, por meio de abordagem, entrega e recolhimento dos formulários aos cooperados de forma presencial pelos pesquisadores. O instrumento de pesquisa utilizado foi adaptado do modelo de Lenzi (2008), consistindo em 42 questões.

O questionário teve como objetivo verificar as principais competências e características dos empreendedores rurais estabelecendo um escore de competências comumente presentes nos pesquisados, por meio de 30 questões relacionadas às competências empreendedoras, bem como, dados sócios econômicos, dentre eles: gênero, grau de instrução, idade, renda, entre outros.

As 30 perguntas permitem a identificação das dez competências a partir de uma escala de três perguntas para cada uma das competências propostas por Lenzi em seu estudo. Atribuindo uma nota na escala ordinal (de 1 a 5) para cada afirmação do instrumento, o respondente obterá após a soma das respostas uma pontuação que poderá variar de 3 a 15. A presença de determinada competência é definida pela soma de, no mínimo, 12 pontos por competência (BRACHT e WERLANG, 2015). 
De acordo com Lenzi (2008), as competências empreendedoras identificadas por meio do instrumento são: Busca de Oportunidades e Iniciativa (BOI); Correr Riscos Calculados (CRC); Exigência de Qualidade e Eficiência (EQE); Persistência (PER); Comprometimento (COM); Busca de Informação (BDI); Estabelecimento de Metas (EDM); Planejamento e Monitoramento Sistemáticos (PMS); Persuasão e Rede de Contatos (PRC) e Independência e Autoconfiança (IAC). Para o presente estudo, foi incluído na adaptação do questionário a variável Competência Empreendedora para Sustentabilidade, intitulada CES.

$\mathrm{Na}$ terceira etapa da pesquisa os questionários foram tabulados e as respostas consolidadas em uma planilha do software Microsoft Excel $^{\circledR}$ e foram analisadas conforme os critérios descritos a seguir no item resultados e discussão.

\section{RESULTADOS E DISCUSSÃO}

Nesta seção são apresentados os dados obtidos por meio da aplicação dos questionários ilustrados em tabelas e gráficos, bem como análises e correlações com outros estudos que abordaram o tema objeto da presente pesquisa.

\subsection{PERFIL DA AMOSTRA:}

Dentre os associados entrevistados, a faixa etária com maior incidência correspondeu à acima dos 50 anos de idade, somando 62,96\% do total. Apenas um respondente possuía menos de 24 anos. No aspecto que se refere ao gênero, $16(59,26 \%)$ se autodeclararam do gênero masculino e 11 (40,74\%) se autodeclararam mulheres. Quanto à demografia escolaridade, 59\% cursaram ao menos o Ensino Médio completo, sendo que 11\% desses possuem Ensino Superior e/ou pós-graduação. Esses resultados indicam nível educacional superior à média nacional. De acordo com os dados do IBGE referentes ao ano de 2016, o equivalente a $51 \%$ da população com idade superior a 25 anos possui somente o Ensino Fundamental completo (IBGE, 2016).

As atividades rurais se concentram expressivamente na relação agricultura e agroindústria, respondendo por $62,96 \%$ das entrevistas e 37,04 exploram somente uma das atividades supracitadas. Apurou-se um faturamento mensal de até R \$ 4.770,00 na participação de $81,48 \%$ dos entrevistados. 
Quanto ao estado civil, constatou-se que $92,59 \%$ dos respondentes estão casados e $96,30 \%$ utilizam-se da mão de obra familiar para manter as operações dos empreendimentos.

Quando interpelados em relação a auto percepção sobre o empreendedorismo, a grande maioria, $96,30 \%$ dos entrevistados, afirmaram que se consideram empreendedores.

Quanto ao tamanho das propriedades rurais, os dados foram apresentados na tabela 01:

Tabela 01 - Tamanho das propriedades:

\begin{tabular}{ccc}
\hline Tamanho propriedade (ha - hectares) & Quantidade & \% \\
\hline $\mathbf{0 , 5}$ a 10 & 16 & 59,26 \\
De 10,01 a 15 & 6 & 22,22 \\
De 15,01 a 20 & 4 & 14,81 \\
De 20,01 a 25 & 1 & 3,70 \\
\hline Total & $\mathbf{2 7}$ & $\mathbf{1 0 0 , 0 0}$ \\
\hline
\end{tabular}

Fonte: Dados da pesquisa 2018.

\subsection{ANÁLISE DAS COMPETÊNCIAS EMPREENDEDORAS}

Subsidiados pelas respostas obtidas pela aplicação dos 27 questionários, destacaram-se principalmente três competências, são elas: PER (Persistência) presente em 100\% dos entrevistados; a competência COM (Comprometimento), que atinge 100\% dos respondentes e, por fim, CES (Competência Empreendedora para Sustentabilidade), com destaque para $96,30 \%$ dos associados pesquisados. O resultado da competência empreendedora para sustentabilidade condiz com a afirmação de Barros Neto (2015), em que esse enfatiza que é preciso entender que existe a possibilidade de fazer as coisas da forma correta com lucro e estar atento às oportunidades que estão em todos os lugares. Certamente, quando o empreendedor age com responsabilidade social, abrem-se mais oportunidades (BARROS NETO, 2015).

Já as competências encontradas em menor intensidade foram: a BOI (Busca de Oportunidade e Iniciativa), presente em apenas 59,26\% das entrevistas; a EQE (Exigência de Qualidade e Eficiência), e a competência EDM (Estabelecimento de Metas), com $88,89 \%$ de respondentes. No que tange ao estabelecimento de metas, os resultados são convergentes com a pesquisa conduzida por Wissmann (2017), que estudou as competências dos microempreendedores. Concluiu-se que esses creditam à organização e 
REMIPE

ao planejamento das atividades. Inclui-se, aqui, o estabelecimento de metas, nessa respectiva ordem, maior importância. Parece existir um acordo de que essas duas competências, caso sejam trabalhadas, podem gerar bons resultados no negócio.

A Figura 1 apresenta a análise geral do aparecimento das competências empreendedoras entre os respondentes, bem como a média de pontuação por competência:

Figura 1 - Análise das competências empreendedoras:

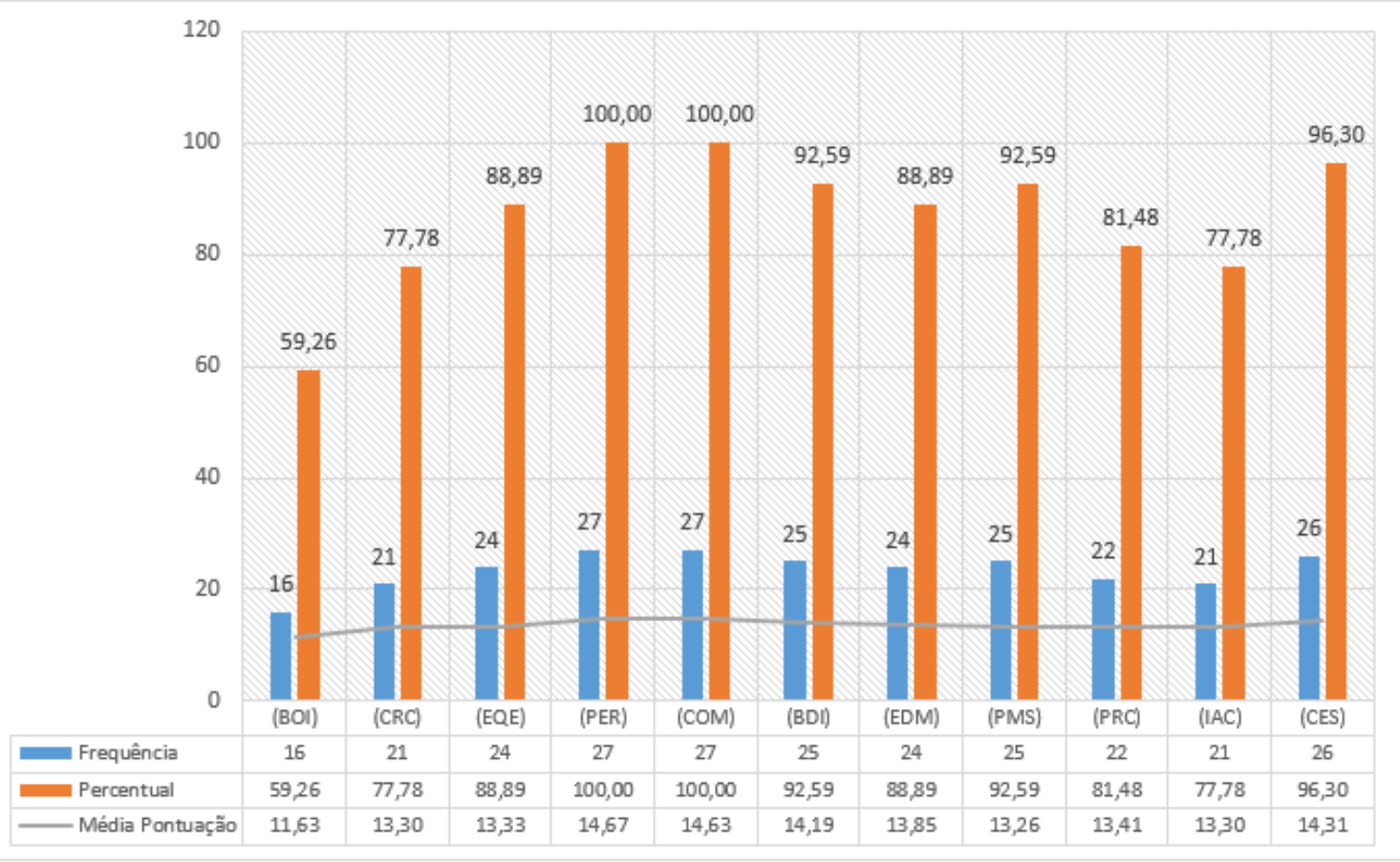

Fonte: Dados da pesquisa (2018)

Para evidenciar a presença de determinada competência, Lenzi (2008) propõe que a soma entre a escala ordinal de 1 a 5 apresente um resultado mínimo de 12 pontos. Dessa forma, as médias de pontuação obtidas pelo presente estudo podem ser consideradas satisfatórias, pois com exceção de uma competência (BOI), todas as demais se estabeleceram acima de 13 pontos, em média, e algumas competências se destacam mais do que outras em relação à média da pontuação.

Quanto ao grau de escolaridade, a pesquisa evidenciou que a maior parte de competências se concentrou no nível Ensino Médio completo com 56\% de respondentes, seguido pelo Ensino Médio incompleto com 25\%. O Ensino Fundamental obteve 13\% dos entrevistados e o Ensino Superior somente 6\%. 
Nesse sentido, o Quadro 3 apresenta o cruzamento das competências que foram evidenciadas no perfil empreendedor dos pesquisados, ou seja, que atingiram o mínimo de 12 pontos, com a demografia e escolaridade:

Quadro 03 - Análise das competências empreendedoras versus escolaridade:

\begin{tabular}{|c|c|c|c|c|c|c|c|c|c|c|c|c|c|c|c|c|c|c|c|c|}
\hline Escolaridade & 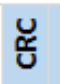 & $\%$ & 岁 & $\%$ & 嗂 & $\%$ & ర్ర & $\%$ & $\overline{0}$ & $\%$ & 空 & $\%$ & $\sum_{a}^{n}$ & $\%$ & $\frac{u}{\frac{\pi}{\alpha}}$ & $\%$ & u & $\%$ & 岂 & $\%$ \\
\hline Ensino Fundamental & 3 & 14 & 4 & 17 & 5 & 19 & 5 & 19 & 5 & 20 & 4 & 17 & 5 & 20 & 2 & 9 & 4 & 19 & 4 & 15 \\
\hline Ensino Médio incompleto & 6 & 29 & 6 & 25 & 6 & 22 & 6 & 22 & 6 & 24 & 6 & 25 & 6 & 24 & 5 & 23 & 5 & 24 & 6 & 23 \\
\hline Ensino Médio & 11 & 52 & 12 & 50 & 13 & 48 & 13 & 48 & 11 & 44 & 12 & 50 & 11 & 44 & 13 & 59 & 11 & 52 & 13 & 50 \\
\hline Ensino Superior & 1 & 5 & 1 & 4 & 2 & 7 & 2 & 7 & 2 & 8 & 1 & 4 & 2 & 8 & 1 & 5 & 1 & 5 & 2 & 8 \\
\hline Pós-graduação & 0 & 0 & 1 & 4 & 1 & 4 & 1 & 4 & 1 & 4 & 1 & 4 & 1 & 4 & 1 & 5 & 0 & 0 & 1 & 4 \\
\hline Total & $21^{\prime}$ & 100 & 24 & 100 & 27 & 100 & 27 & 100 & 25 & 100 & 24 & 100 & 25 & 100 & 22 & 100 & 21 & 100 & 26 & 100 \\
\hline
\end{tabular}

Fonte: Dados da pesquisa (2018)

Como os resultados desta pesquisa já evidenciaram maior destaque para o nível de escolaridade Ensino Médio completo. Na análise individual das competências também apresentou maior correlação desse nível com todas as competências presentes na amostra. Dentre as variações, a competência Persuasão e Rede de Contatos (PRC) foi a que apresentou maior participação com $59 \%$ e, com menor participação, estão as competências Planejamento e Monitoramento Sistemáticos (PMS) e Busca de Informação (BDI), ambas com 44\%.

$\mathrm{Na}$ análise dos demais níveis de escolaridade, o Ensino Médio incompleto teve maior relação com a competência Correr Riscos Calculados (CRC), com 29\%. Observase um equilíbrio de respostas nesse nível que variaram entre $22 \%$ a $29 \%$ das respostas.

Quanto ao nível Ensino Fundamental apresentou também um equilíbrio de respostas, variando entre 14 a 20\%, com exceção para a competência Persuasão e Rede de Contatos (PRC), que obteve 9\%. Os níveis Ensino Superior e pós-graduação foram as que tiveram menor participação e variaram entre 0 a $8 \%$ das respostas.

Além da demografia escolaridade, efetuou-se também o cruzamento das competências com o faturamento bruto mensal da propriedade, como demonstrado no Quadro 4: 
REMIPE

Quadro 04 - Análise das competências empreendedoras versus faturamento:

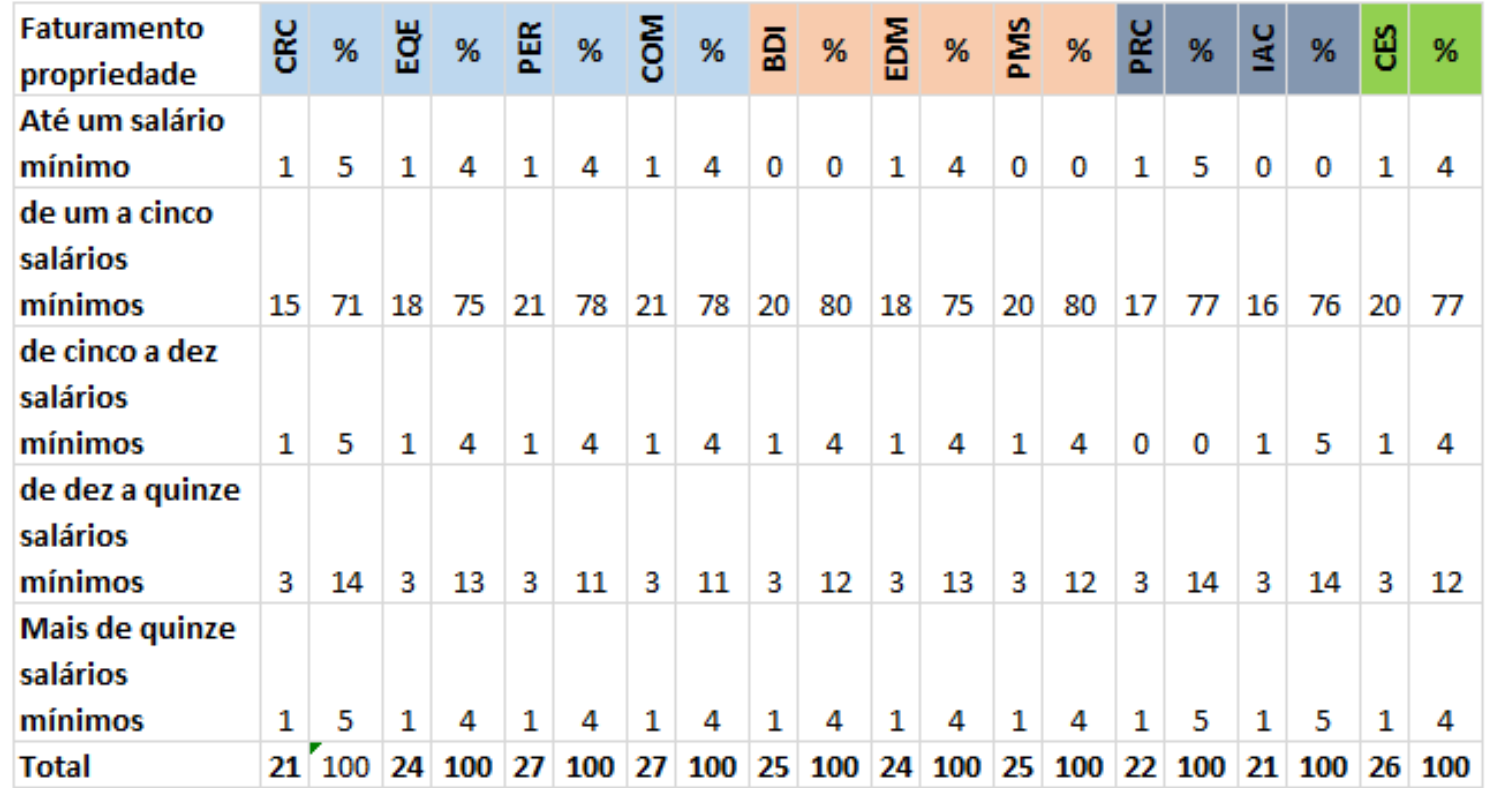

Fonte: Dados da pesquisa (2018)

Nessa análise, o maior destaque foi a relação das competências com a faixa de faturamento de 1 a 5 salários mínimos, que variaram entre 71 a 80\% das participações, demonstrando equilíbrio entre as competências presentes. No entanto, as que tiveram maior número de respondentes foram: Busca de Informação (BDI) e Planejamento e Monitoramento Sistemáticos (PMS), representando 80\% para ambas. Seguidos pelas competências Persistência (PER) e Comprometimento (COM), com 78\% cada.

Em ordem decrescente de participação, a segunda maior está relacionada ao nível de faturamento que varia de 10 a 15 salários mínimos e, também, apresentou equilíbrio nessa faixa entre as competências, variando entre 11 a $14 \%$ das respostas. As demais faixas apresentaram baixa participação e variaram entre 0 a $5 \%$ os respondentes.

\section{CONSIDERAÇÕES FINAIS}

O estudo evidenciou a importância do agronegócio no contexto nacional, bem como a relação das sociedades cooperativas como agentes de transformação do cenário econômico por meio da geração e distribuição de renda entre seus associados. Outra importante temática abordada no estudo consiste na relação entre as agroindústrias e o perfil empreendedor apresentados pelos cooperados.

Como a agricultura por natureza caracteriza-se como uma atividade de risco, a identificação das competências empreendedoras dos agricultores traz uma relevante 
contribuição na identificação das principais forças modeladoras do perfil dos respectivos agentes que contribuem ativamente no fortalecimento do agronegócio e, consequentemente, da economia em nível regional e nacional.

Os resultados do presente estudo mostram que quanto ao perfil, a maioria dos empreendedores rurais $(59,26 \%)$ é do sexo masculino, desenvolvem a atividade rural de agricultura e agroindústria, com a predominância de propriedades rurais entre 5 a 10 hectares. Grande parte dos empreendedores entrevistados possui Ensino Médio completo $(56 \%)$ e o faturamento bruto mensal das propriedades se concentra entre a faixa de 1 a 5 salários mínimos, perfazendo uma renda que varia de $\mathrm{R} \$ 955,00$ a $\mathrm{R} \$ 4.770,00$.

$\mathrm{Na}$ identificação das competências, pôde-se apurar, mediante esta pesquisa, que as de maior destaque foram PER (Persistência) presente em 100\% dos entrevistados, também a competência COM (Comprometimento), que atinge 100\% dos respondentes, e por fim, CES (Competência Empreendedora para Sustentabilidade), com destaque para $96,30 \%$ dos associados pesquisados. Já as competências encontradas em menor intensidade foram a BOI (Busca de Oportunidade e Iniciativa), presente em apenas 59,26\% das entrevistas; a EQE (Exigência de Qualidade e Eficiência) e a EDM (Estabelecimento de Metas), com 88,89\% de respondentes.

Como principal limitação do estudo, cabe destacar o número reduzido da amostra, que impossibilita inferências estatísticas mais sofisticadas, bem como o volume de estudos que abordam a variável competências empreendedoras focadas para o agronegócio e agroindústria familiar, dificultando a discussão dos resultados com outros autores.

Recomenda-se aprofundar a temática abordando as competências empreendedoras presentes no agronegócio para uma amostra mais abrangente de agricultores, bem como maior diversidade de atividades rurais, envolvendo além das agroindústrias a agricultura, pecuária, integrações na criação de animais e o turismo rural.

O estudo tem sua relevância confirmada na medida em que identifica as competências empreendedoras prevalentes nos produtores rurais, de tal modo que amplia o leque de estudos que abordam o tema e contribuem com resultados convergentes para os estudos de Lenzi (2008), bem como Brachdt e Werlang (2015). Com isso, lança indicativos para novos estudos acerca do tema empreendedorismo. 


\section{REFERÊNCIAS}

ABBADE, E. B. O papel do agronegócio brasileiro no seu desenvolvimento econômico. Gepros: Gestão da Produção, Operações e Sistemas, 9(3), 149, 2014.

ALIGLERI, L.; ALIGERI, L. A.; KRUGLIANSKAS, I. Gestão socioambiental: responsabilidade e sustentabilidade do negócio. São Paulo: Editora Atlas AS, 2009.

BACHA, C. J. C. Economia e política agrícola no Brasil. Editora Atlas AS, 2012.

BARBIERI, J. C. Gestão ambiental empresarial: conceito, modelos e instrumento. $2^{\mathrm{a}}$ ed. São Paulo: Editora Saraiva, 2007.

BARON, R. A.; SHANE, S. A. Empreendedorismo: Uma visão do processo. Editora Cengage Learning, 2010

BARROS NETO, J. P. As Vantagens do Empreendedorismo Versus a Dependência do Assistencialismo Filantropia: Por que Estimular o Empreendedor e Evitar o Assistido? REMIPE-Revista de Micro e Pequenas Empresas e Empreendedorismo da Fatec, 1(1), 78-94, 2015. DOI. https://doi.org/10.21574/remipe.v1i1\%20jan-jun

BLANCO, E. S. O turismo rural em áreas de agricultura familiar: as" novas ruralidades" e a sustentabilidade do desenvolvimento local. Caderno Virtual de Turismo, 4(3), 2006.

BONI, V.; QUARESMA, J. Aprendendo a entrevistar: como fazer entrevistas em Ciências Sociais, 2(3), 68-80, 2005.

BRACHT, D. E.; WERLANG, N. B. Competências empreendedoras: uma investigação com produtores rurais catarinenses. Revista de Empreendedorismo e Gestão de Pequenas Empresas, 4(1), 101-124, 2015. Doi: 10.14211/41130

BRANDALISE, L. T et al. Educação e gestão ambiental: sustentabilidade em ambientes competitivos. $2^{\mathrm{a}}$ ed. Cascavel, Paraná: Ed. DRHS, 2017.

CASTRO, A. M. G. Análise da competitividade de cadeias produtivas. Workshop Cadeias Produtivas E Extensão Rural Na Amazônia, 2000.

CASTRO, C. N. de. Pesquisa Agropecuária Pública Brasileira: Histórico E Perspectivas. IPEA - Boletim Regional, Urbano E Ambiental, 15, 45-52, 2016. Disponível em: http://repositorio.ipea.gov.br/bitstream/11058/7104/1/BRU_n15_Pesquisa.pdf

DALMORO, M. et al. As lógicas dos produtores invisíveis: significados culturais na produção agrícola familiar. Read Revista Eletrônica de Administração 23 (3), 92-115, 2017. Recuperado 21 janeiro de 2018 de http://www.scielo.br/scielo.php?script=sci_arttext\&pid=S1413$23112017000300092 \& \operatorname{lng}=\mathrm{pt \& t} \operatorname{lng}=\mathrm{pt}$ 
FERREIRA, J. C. Análise do nível de gestão da sustentabilidade da rede hoteleira de Foz do Iguaçu, PR, utilizando como suporte a contabilidade gerencial. Cascavel. Tese de Mestrado, UNIOESTE, 2017.

Fronzaglia, T. O Papel da Pesquisa Agropecuária Pública nas Inovações Organizacionais na Agricultura: O Caso das Indicações Geográficas. Tese de Doutorado, UNICAMP, 2015.

GASQUES, J. G. et al. Desempenho e crescimento do agronegócio no Brasil. Ipea Issn 1415-4765, 39, 2004.

INSTITUTO BRASILEIRO DE GEOGRAFIA E ESTATÍSTICA - IBGE. Pesquisa nacional por amostra de domicílios (PNAD), 2016. Recuperado em 25 fevereiro, 2018, de https://agenciadenoticias.ibge.gov.br/agencia-noticias/2013-agencia-denoticias/releases/18992-pnad-continua-2016-51-da-populacao-com-25-anos-ou-mais-dobrasil-possuiam-apenas-o-ensino-fundamental-completo.html

Censo Agropecuário 2006. Recuperado 21 de janeiro de 2018, de http://www.ibge.gov.br/home/estatistica/economia/agropecuaria/censoagro/agri_familiar_ 2006 2/default.shtm

LEI $\mathbf{n}^{0} \mathbf{1 1 . 3 2 6}$ de 24 de julho de 2006. Recuperado 5 de julho de 2017, de http://www.planalto.gov.br/ccivil_03/_ato2004-2006/2006/lei/111326.htm.

LENZI, F. C. Os empreendedores corporativos nas empresas de grande porte dos setores mecânico, metalúrgico e de material elétrico/comunicação em Santa Catarina: um estudo da associação entre tipos psicológicos e competências empreendedoras reconhecidas. Tese de Doutorado, USP, 2008.

LEVY P.S.; LEMESHOW S. Sampling for health professionals. Belmont: LLP, 1980.

MANZANAL, M.; SCHENEIDER, S. Agricultura Familiar y Políticas de Desa rrollo Rural en Argentina y Brasil (análisis comparativo, 1990-2010). Revista Interdisciplinaria de Estudios Agrarios, Vol. 34, 2011. Recuperado de http://www.filo.uba.ar/contenidos/investigacion/institutos/geo/pert/Manzanal schneider 2011.pdf

MELLO, M. A. de; SCHENEIDER, S. A produção de "Novidades" como alternativa à crise pelos agricultores do Oeste de Santa Catarina. Desafio Online, 1(3), 1-18, 2013. Recuperado de http://www.spell.org.br/documentos/ver/17613/a-producao-de---novidades----como-alternativa-a-crise-pelos-agricultores-do-oeste-de-santa-catarina

MELLO, S. C. B. de; LEÃO, A. L. M. de S.; PAIVA JÚNIOR, F. G. de. Competências Empreendedoras de Dirigentes de Empresas Brasileiras de Médio e Grande Porte que Atuam em Serviços da Nova Economia. RAC Revista de Administração Contemporânea 10 (4) 47-69, 2006. Recuperado 21 janeiro de 2018 de http://www.scielo.br/pdf/rac/v10n4/a03v10n4.pdf 
OLIVEIRA, M. A. Valeu! Passos na trajetória de um empreendedor. São Paulo, São Paulo: Livraria Nobel S.A, 1995.

$\begin{array}{lrrrrrrr}\text { ORGANIZAÇO DAS } & \text { COOPERATIVAS } & \text { BRASILEIRAS } & \text { OCB. } & \text { Relatório } & \text { OCB } \\ \text { 2013. } & \text { Recuperado } & 21 & \text { de } & \text { janeiro } & \text { de } & 2018, & \text { de }\end{array}$ http://relatorioocb2013.brasilcooperativo.coop.br/?portfolio=visao-panoramica

PAIVA, K. C. M.; FERREIRA, L. dos S. Competências Gerenciais na área de Tecnologia de Informação: um estudo com gestores de empresas localizadas no Triângulo Mineiro. Revista Gestão \& Tecnologia, 13 (1) 205-229, 2013. Recuperado 21 janeiro de 2018 de http://revistagt.fpl.edu.br/get/article/view/484

POSSENTI, M. A. Proposta de uma sistemática para apoiar a gestão econômicofinanceira de agroindústrias familiares de pequeno porte. Universidad Federal do Rio Grande do Sul, 2013. Recuperado de http://hdl.handle.net/10183/28818

PROTIL, R. M. A. X.; BENEDITO, A.; SOUZA, K. Agroindustrias Utilizando um Modelo de Scorecard Dinâmico. RCO-Revista de Contabilidade E OrganizaçõesFEARP/USP, 3(5), 62-79, 2009.

SANTOS, A. R. Metodologia científica: a construção do conhecimento. Rio de Janeiro: DP\&A, 1999.

SCHUMPETER, J. A. A teoria do desenvolvimento econômico. São Paulo: Editora Abril, 1982.

SILVA, L. M. R.; PEIXOTO, H.; KHAN, A. S. Viabilidade econômica de implantação de agroindústria de polpa de frutas no estado do Ceará. Revista Econômica do Nordeste, 29(2), 175-193, 1998.

SILVEIRA, D. T.; CÓRDOVA, F. P. A pesquisa científica. Métodos de pesquisa. 2009. https://doi.org/10.1590/S1677-54492006000400001

SILVEIRA, T.S.; PASSOS, D. F. O.; MARTINS, I. A. D. M. Empreendedorismo x startup: um comparativo bibliométrico de 1990 a 2016. REMIPE-Revista de Micro e Pequenas Empresas e Empreendedorismo da Fatec Osasco, 3(2, jul-dez), 304-322, 2017. DOI. https://doi.org/10.21574/remipe.v3i2,\%20jul-dez

SOARES, T.; JACOMETTI, M. Strategies That Add Value in Agribusiness Segments in Brazil : a Descriptive Study. Reen - Estratégia E Negócios, 8(43), 93-120, 2015.

SOUZA, E. C. L. de; GUIMARÃES, T. A. Empreendedorismo além do plano de negócios. São Paulo, São Paulo: Editora Atlas AS, 2006.

STEFANELO, E. Agronegócio mundial e brasileiro. Vitrine da Conjuntura, Curitiba, 1(1), 2008. 
TARIFA, M. R.; SCHALLENBERGER, E. Gestão Cooperativa, Ambiente Institucional E Sociocultural: O Caso Brasil-Paraguai. RESR, Piracicaba-SP, 54(1990), 615-634, 2016. https://doi.org/10.1590/1234-56781806-94790540402

WISSMAN, A. D. M. Competências do Microempreendedor Individual. REMIPERevista de Micro e Pequenas Empresas e Empreendedorismo da Fatec Osasco, 3(2, jul-dez), 279-303, 2017. DOI. https://doi.org/10.21574/remipe.v3i2,\%20jul-dez

ZANELLA, M. V. et al. Pesquisa e Assistência Técnica Nas Cooperativas Agropecuárias Panaenses. Sistema Ocepar, 1 ed., 72, 2016. 